\title{
Leukoencephalopathy with cerebral calcifications and cyst: Labrune syndrome
}

\author{
Leucoencefalopatia com cistos e calcificações cerebrais: síndrome de Labrune \\ André Luiz Santos Pessoa ${ }^{1}$, Amanda do Vale Monteiro², Rafael Fonseca de Queiroz², George Linard \\ Malveira ${ }^{3}$, Fernando Kok ${ }^{4}$
}

\begin{abstract}
${ }_{1}^{1}$ Professor da Faculdade de Medicina da Universidade de Fortaleza, UNIFOR, Fortaleza CE; Médico Neurologista Infantil do Hospital Estadual Albert Sabin, SESA-CE; Médico Colaborador do grupo de neurogenética do Centro de Estudos do Genoma Humano, ICB-USP, São Paulo SP, Brazil;

${ }^{2}$ Acadêmico de Medicina da UNIFOR, Fortaleza CE, Brazil;

${ }^{3}$ Neurologista do Hospital Geral de Fortaleza- HGF-SESA-CE, Fortaleza CE, Brazil;

${ }_{4}^{4}$ Professor Livre-Docente do Departamento de Neurologia da Faculdade de Medicina da Universidade de São Paulo, FMUSP, São Paulo SP, Brazil.
\end{abstract}

Correspondence: André Luiz Santos Pessoa; Rua Monsenhor Bruno 289 / apto. 1.303;60115-191 Fortaleza CE - Brasil; E-mail: andrepessoa10@yahoo.com.br Conflict of interest: There is no conflict of interest to declare.

Received in 23 August 2011; Received in final form 26 October 2011; Accepted 01 November 2011

The association of leukoencephalopathy with cerebral calcifications and cysts (LCC), Labrune syndrome is a rare disease, which was first described in $1996^{1}$. LCC is derived from the syndrome called COATS plus or cerebroretinal microangiopathy with calcifications and brain cysts (CRMCC), reported in 1988. We report a case of an adult patient with LCC.

\section{CASE REPORT}

Patient, male, 31 years-old, son of non-consanguineous parents, and no perinatal complications, he presents a history of tonic-clonic seizures for seven years. Previously healthy, he sought assistance after the first seizure, showing no changes in neurological examination in post-crisis. The patient had complete blood count, renal and hepatic function, glucose, electrolytes, serology for HIV and toxoplasma gondii negative.
Electrocardiogram and cardiac enzymes were normal. In that occasion, the computed tomography (CT) scan showed a bilateral calcification located in the basal ganglia (Fig C). Brain magnetic resonance imaging (MRI) showed extensive area of leukodistrophia and cysts in both hemispheres, the largest measuring 6.7 versus $4.8 \mathrm{~cm}$, with marginal enhancement after intravenous contrast. The repeated MRI showed progression of the lesions (Fig A and B).

In the same month, the largest brain cyst was surgically removed, and the histopathological examination of the cyst showed foci of dystrophic calcifications and focal accumulations of macrophages xanthomized. There were no signs of malignancy in the sample. The patient evolved with partial control of seizures using carbamazepine $1,800 \mathrm{mg} /$ day and he also performed five surgeries to remove brain cysts. Now, the patient is currently with neurological examination demonstrating cognitive syndrome characterized by a transcortical motor aphasia;
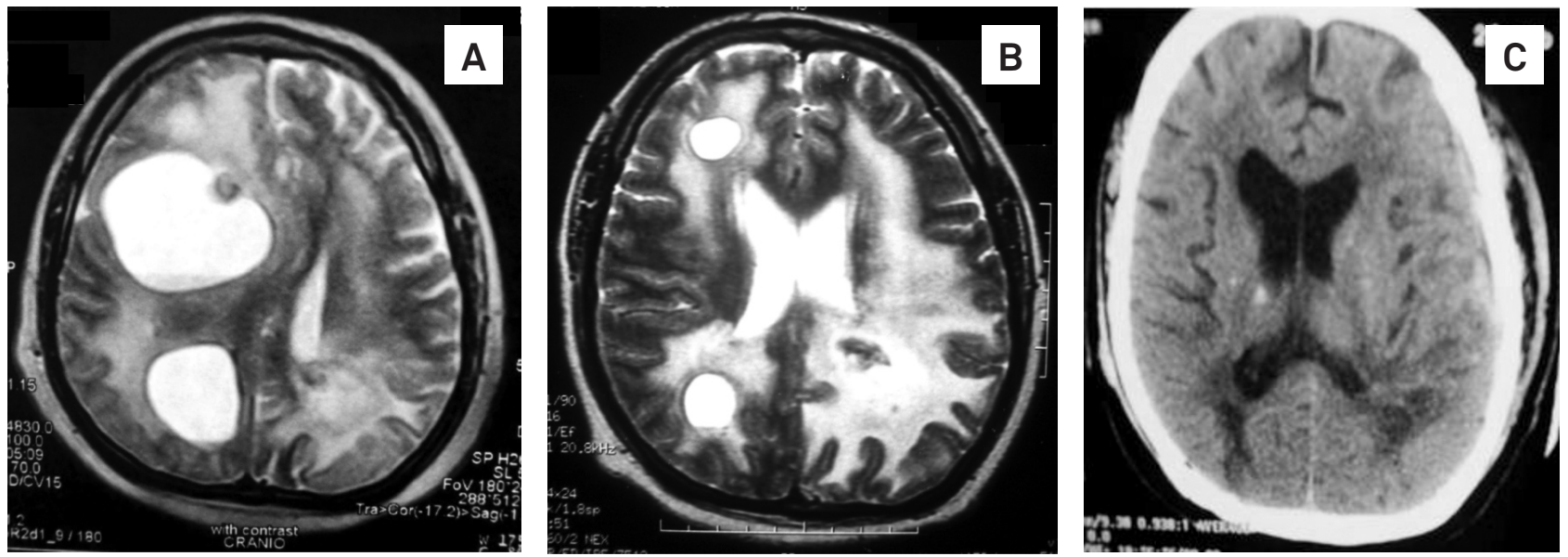

Fig. (A) Brain MRI showing brain cysts in the right hemisphere with midline shift, compression of the lateral ventricles, and white matter changes; (B) MRI with two brain cysts in the right hemisphere and white matter changes; (C) CT scan showing calcifications in the basal ganglia. 
pyramidal syndrome characterized by incomplete hemiparesis on the right hemibody. Myotatic exalted reflexes in the right hemibody and plantar-cutaneous reflex were indifferent.

\section{DISCUSSION}

Reviewing the relevant literature worldwide, Labrune syndrome was considered as a possible diagnosis for the present case $^{2}$. Despite the presence of cysts, calcification, and edema of the white substance found in our patient, suggesting neurocysticercosis, equinecocosis ${ }^{3}$ or neoplasia, there was no serologic or histopathologic confirmation.

This syndrome is characterized by calcifications, leukodystrophy, and formation of parenchymal cysts ${ }^{1}$. Its onset can occur during childhood or adolescence, in an average of 12 years ( 7 months -59 years), but there was not one in adults in Brazil, with neurological signs such as cognitive decline, seizures and pyramidal, extrapyramidal or cerebellar signs ${ }^{1,2}$. Our patient, unlike the other cases reported in literature, presented its first neurological manifestation at the age of 24 . $\mathrm{CT}$ and MRI seen in our case were similar to the cases reported in literature, showing increased signal intensity of the white matter on MRI (T2 and FLAIR), basal ganglia calcification, and development of cysts ${ }^{1-3}$.

Labrune reported the results of histopathology with rearrangement involving the microvessels, whereas perivascular foci of calcifications, hyaline deposits, and formation of Rosenthal fibers seem to be compatible with this change ${ }^{1}$. The histopathological findings of our patient were consistent with LCC. According to them, the likely primary pathologic feature is a rearrangement involving the microvessels and the formation of Rosenthal fibers ${ }^{1,4}$.

In conclusion, the etiology of LCC remains unknown. In spite of relatively characteristic findings in imaging and histopathological examination, there is no uniformity in the clinical findings noted in the published articles. It can be speculated that the later age of onset, normal intelligence and slow progression, like in our patient, may indicate the shape of this rare disease in adults.

\title{
References
}

1. Labrune P, Lacroix C, Goutieres F, et al. Extensive brain calcifications, leukodystrophy, and formation of parenchymal cysts: a new progressive disorder due to diffuse cerebral microangiopathy. Neurology 1996;46:1297-1301.

2. Nagae-PoetscherLM,BibatG,PhilippartM,etal.Leukoencephalopathy, cerebral calcifications and cysts: new observations. Neurology 2004;62:1206-1209.
3. Sener U, Zorlu Y, Men S, Bayol U, Zanapalioglu U. Leukoencephalopathy, cerebral calcifications, and cysts. Am J Neuroradiology 2006; 27:200-203.

4. Briggs TA, Abdel-Salam GMH, Balicki M, et al. Cerebroretinal microangiopathy with calcifications and cysts (CRMCC). Am J Med Genet 2008;146:182-190.

\section{Metamorphopsia associated with topiramate for migraine prevention}

\author{
Metamorfopsia associada ao uso de topiramato para prevenção de enxaqueca \\ Ana Claudia Rodrigues de Cerqueira ${ }^{1}$, Antônio Egídio Nardi²
}

${ }^{1}$ Doctoral student in Panic and Respiration Laboratory, Institute of Psychiatry, Federal University of Rio de Janeiro (UFRJ), INCT Translational Medicine (CNPq), Rio de Janeiro RJ, Brazil;

${ }^{2}$ Full Professor in the Panic and Respiration Laboratory, Institute of Psychiatry, UFRJ, INCT Translational Medicine (CNPq), Rio de Janeiro RJ, Brazil. Correspondence: Ana Claudia Rodrigues de Cerqueira; Laboratório de Pânico e Respiração, Universidade Federal do Rio de Janeiro; Rua Visconde de Pirajá 407/702; 22410-003 Rio de Janeiro RJ - Brasil; E-mail: anacerqueira@globo.com

Conflict of interest: There is no conflict of interest to declare.

Received 07 September 2011; Received in final form 02 October 2011; Accepted 10 October 2011

A 33-year-old woman (registration 70-247/ IPUBUFRJ) has had recurring headaches since the age of 18 . She described more right-sided than left-sided throbbing, which could be severe and associated with nausea, light and noise sensitivity, and vomiting. She has had a visual aura, seeing "zig-zags", lasting for 20 to 30 minutes before the headaches. The only preventive measure she had taken in the past was divalproex sodium, with good efficacy. Because of the weight gain as a side effect, she refused to take it again. Her body mass index (BMI) was 35.3. She was started on preventive therapy with topiramate at 25 mg daily for two weeks that was to be increased weekly 